\author{
Military Technical College \\ Kobry El-Kobbah, \\ Cairo, Egypt.
}

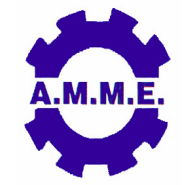

\title{
MONITORING SAND PARTICLES IN TWO-PHASE FLOW WITH ACOUSTIC EMISSION
}

\author{
M. E. El-Alej ${ }^{*}$, D. Mba* and T. Yan*
}

\begin{abstract}
This paper presents an experimental investigation using acoustic emission (AE) technology to monitor sand transportation in two-phase flow. The initial investigation consisted of a preliminary experiment where a single sand particle was dropped from a height onto metal plates to provide a basis for monitoring particle impingement on metal pipes in two-phase or three-phase flow systems. Further investigations were undertaken on two phase (air-sand) flow in a horizontal pipe for varying Superficial Gas Velocities (VSG). The objective of this research programme is to develop a simple, non-invasive technique for monitoring of sand particle concentration levels in multi-phase flow conditions. The experimental findings show that $A E$ absolute energy can be correlated with the size of sand particles, number of sand particles and VSG.
\end{abstract}

\section{KEY WORDS}

Acoustic Emission (AE), multi-phase flow, sand monitoring, condition monitoring.

* School of Engineering, Cranfield University, Cranfield, Bedfordshire, MK43 OAL, U.K. Email for correspondence: m.elalej@cranfield.ac.uk 


\section{INTRODUCTION}

A pipe burst or explosion is a disastrous event in the oil and gas production industry. In low-pressure gas pipeline transportation, pipe bursts or leaks are often attributed to sand particle impingement and rubbing on the pipe wall which can cause significant material thickness losses. This can lead to such failures as bursting and leaking with consequent and loss of production time. The damage caused by the sand particles depends upon factors such as the pipe material, particle velocity and the incident angle of the eroding particles [1].

There is need for multiphase flow measurement in different industries such as the oil and gas production industry to provide continuous monitoring of well performance to enable better reservoir exploitation/drainage. Multiphase measurement techniques are classified mainly as either non-invasive or invasive. Invasive techniques are used inside the pipes and in applications where the use of non-invasive technique is not preferable due to difficulty or high cost. Heat transfer and needle probes are examples of these types of probes. Non-invasive techniques are those which can be used externally (outside the pipe), and are characterised by ease of modification to extend their useful life, and minimise replacement costs. They also provide the potential of field checking or verification of a fixed meter's performance. Some of these techniques are based on pressure drop, ultrasonic and AE techniques.

A key aspect of $\mathrm{AE}$, in comparison to other NDT techniques, is that the signals are produced within the material itself. AE methods have the capability to detect dynamic processes that relate to the degradation in integrity of structures. The application of AE technology as a monitoring tool in two-phase gas-liquid and three-phase gasliquid-sand flow is in its infancy; however, it is now gaining attention, given the advantages of $A E$ technology, such as the ability to be fitted non-intrusively to pipes or containers [2].

$\mathrm{AE}$ is defined as the class of phenomena whereby transient elastic waves are generated by the rapid release of energy from localized sources within a material [7]. The elastic waves, typically in the frequency range from $25 \mathrm{kHz}$ to $1 \mathrm{MHz}$ propagate through the material and can be detected by an $A E$ sensor [6]. Many recent publications on the applications of $\mathrm{AE}$ show that they lead to reliable quantitative results though there are challenges in their application [8].

Previously, AE technology has been attempted in monitoring bubble phenomenon in two phase gas-water systems $[3,4,5]$ and it has been demonstrated that $A E$ technology is capable in detecting a single bubble activity from inception to burst, and the AE signals successfully correlated with bubble size. Al-Lababidi et al., [6] have successfully correlated AE with Gas Volume Fraction (GVF) and Superficial Gas Velocity (VSG) in two-phase gas-liquid flow in a horizontal pipeline. They found that the higher the VSG in gas-water flow system, the higher the absolute value of the AE. However, no attempt to date has specifically related AE to monitor twophase gas-sand flow systems or correlate the $A E$ with the size of the sand particle for a range of VSG streams. 
This study presents an experimental investigation into the applicability of $A E$ for detecting sand particle impact on pipe walls and correlating $A E$ activity with sand concentration levels for varying VSG. In both cases the technique is non-intrusive.

It is believed that this research is make a significant contribution towards the advancement of $A E$ technology as a practical tool for monitoring flow in a two-phase and three-phase systems.

\section{LITERATURE REVIEW}

Al-Lababidi et al., [12] used a condition monitoring system to investigate the sand transport characteristics and identify the sand minimum transport condition (MTC) in sand-water and in sand-air-water multiphase flows in horizontal pipelines. The condition monitoring technique included a data acquisition system NI USB6210, to record parameters such as air volumetric flow rate, water, temperature, differential pressure, and line pressure. The study showed that the MTC was influenced by the gas supply which can cause a change of flow regime and water flow condition. The concentration of sand had a significant impact on the sand transport condition because the sand transport characteristics change with sand concentration. In horizontal air-water flows, the MTC mainly occurred in both regimes as hydrodynamic slug and stratified wavy flow.

Addali et al., [6] successfully correlated AE with GVF and VSG in two-phase gasliquid flows in a horizontal pipeline. They found that a gradual increase in the level of the $A E$ energy received by the $A E$ sensor was caused by an increase of superficial gas and liquid velocities. AE activity was more sensitive at the top of the pipe than at the bottom due to buoyancy of gas bubbles. GVF and AE generated from two-phase flow were correlated for different internal pipe surface roughness conditions. The smoother the internal surface of the pipe, the lower the turbulence and consequently relatively lower $A E$ levels. Finally, observations of correlation between $A E$ and liquid viscosity suggest the possible applicability of $A E$ for monitoring changes in fluid viscosity in-situ.

\section{PRELIMINARY EXPERIMENT FALL IMPACT TEST}

This preliminary experiment was performed to provide a basis for the application of $A E$ technology to detect sand particle impact prior to tests in multiphase flow conditions. The apparatus used is shown in Fig.1. AE signals were detected with a calibrated broad bandwidth piezoelectric transducer/or sensor positioned on the top face of the target plates (aluminium and steel plates). The thickness for the plate used for the preliminary experiment was $1.5 \mathrm{~mm}$. The piezoelectric transducer (Physical Acoustic Corporation type WD) had an operating frequency of $100 \mathrm{kHz}-$ $750 \mathrm{kHz}$ and the pre-amplification at $40 \mathrm{~dB}$ was used. The sampling rate for acquisition of $A E$ waveform was set at $5 \mathrm{MHz}$. A threshold level of $30 \mathrm{~dB}$ was set for the electronic background noise of the acquisition system. In this experiment, the impact point of the sand particle on the plate remains the same throughout the testperiod. 


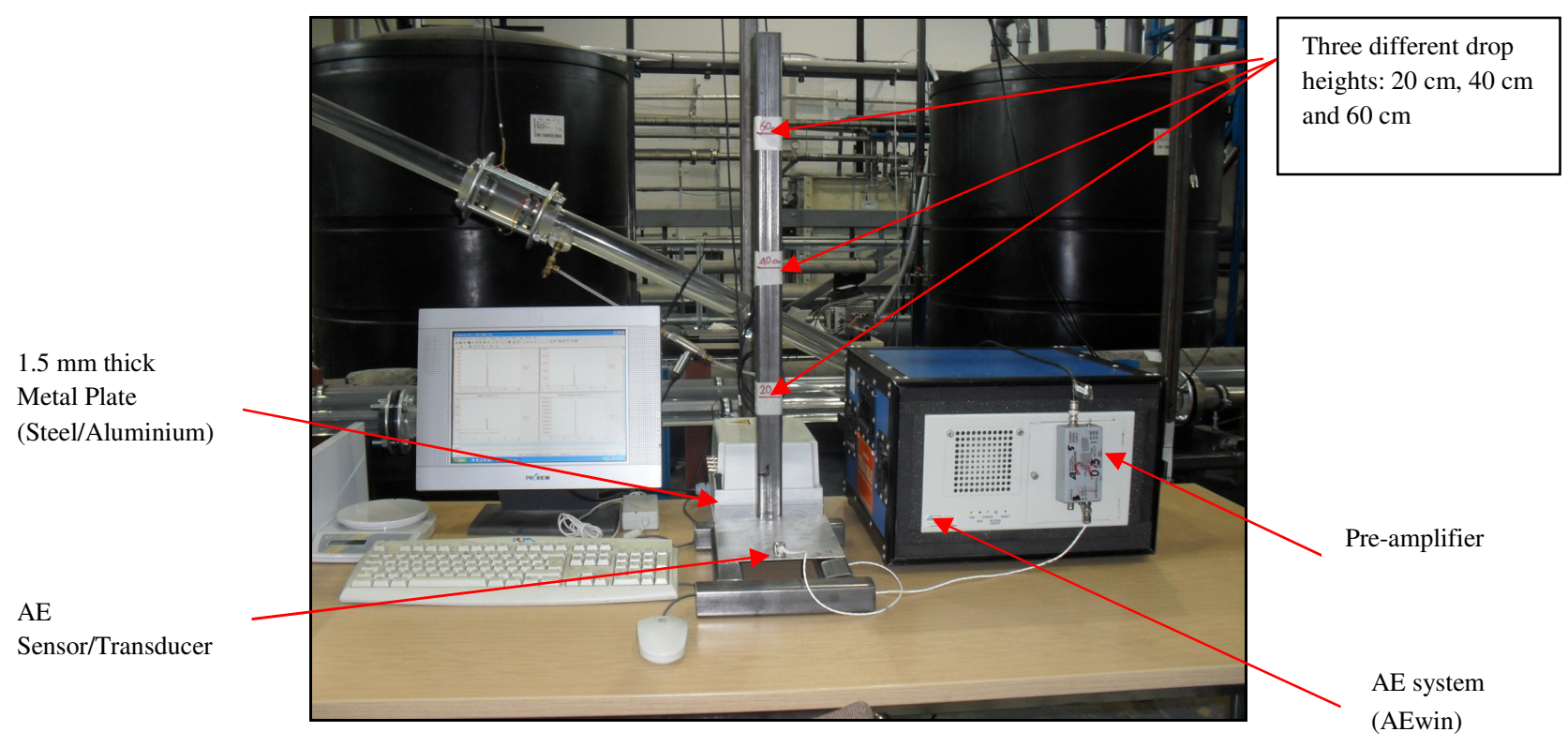

Fig.1. Sand particle impact experiment.

Sand particles of sizes ranging from $150 \mu \mathrm{m}-710 \mu \mathrm{m}$ in diameter, were dropped from a height of $20 \mathrm{~cm}-60 \mathrm{~cm}$ onto the target plates. The AE signal generated by the particle's impact upon the plates was captured and analyzed. A comparison between the $A E$ absolute energy as measured and the therotical potential energy was made.

\section{TWO-PHASE AIR-SAND FLOW TEST}

The experimental investigation involved assessing the concentration of sand impact for a two phase air-sand flow in a horizontal pipe where the VSG had a range of between $5.8 \mathrm{~ms}^{-1}$ to $10.5 \mathrm{~ms}^{-1}$.

The multiphase flow facility was as shown in Figs. 2 and 3, was designed and constructed using an ABS plastic (class E) pipe of $0.05 \mathrm{~m}$ internal diameter. The pipe length is $17 \mathrm{~m}$. The test section consists of a $2 \mathrm{~m}$ Perspex window for observation. The AE sensor used was of pico type with an operating frequency of $100 \mathrm{kHz}-1$ $\mathrm{MHz}$, and was positioned at the bottom of the section of steel pipe. As in the preliminary experiment the sensor had a pre-amplification of $40 \mathrm{~dB}$, and a threshold level of $30 \mathrm{~dB}$ above the electronic background noise was set for the acquisition system. Again as in the preliminary expirement, the sampling rate for acquisition of $\mathrm{AE}$ waveform data was set at $5 \mathrm{MHz}$.

Air is supplied from a screw compressor at a maximum capacity of $400 \mathrm{~m}^{3} / \mathrm{hr}$, and a maximum discharge pressure of 10 barg. Air was metered by a gas flow meter. Two different sand concentrations (one particle and hundred particles) were fed/injected manually through a hole in the plastic pipe. The diameter of sand used was between $355 \mu \mathrm{m}$ and $800 \mu \mathrm{m}$. The test was conducted at different gas superficial velocities ranged from $5.8 \mathrm{~ms}^{-1}$ to $10.5 \mathrm{~ms}^{-1}$. A data-acquisition system was employed to monitor the air volumetric flow rates. 


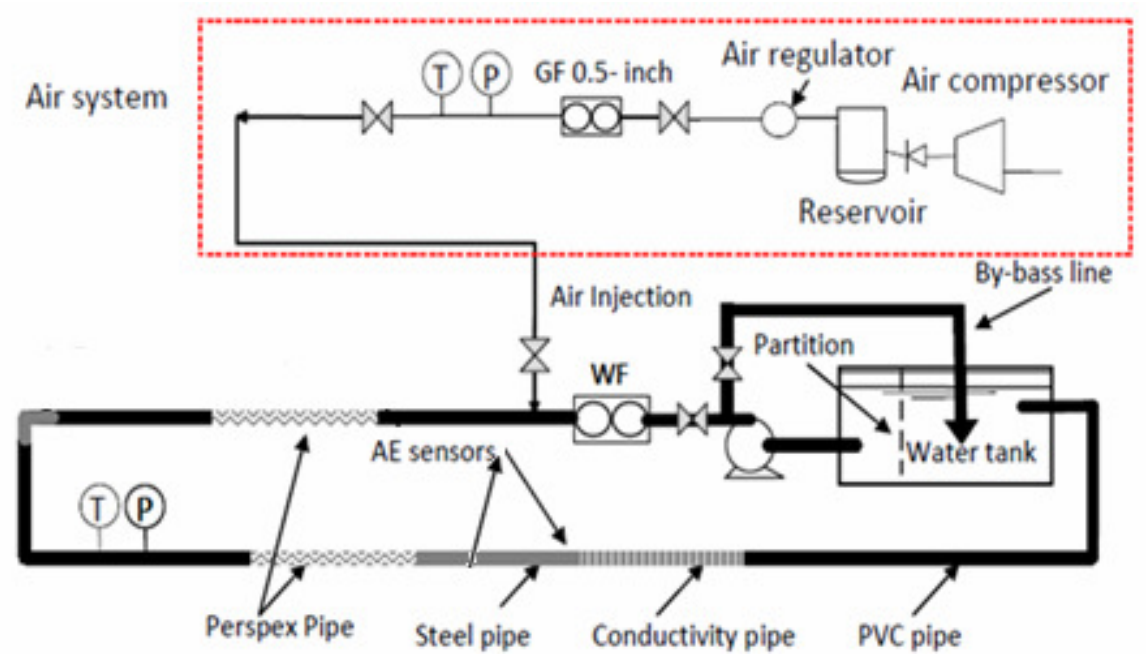

Fig.2. Schematic diagram of two-phase/three-phase test facility.

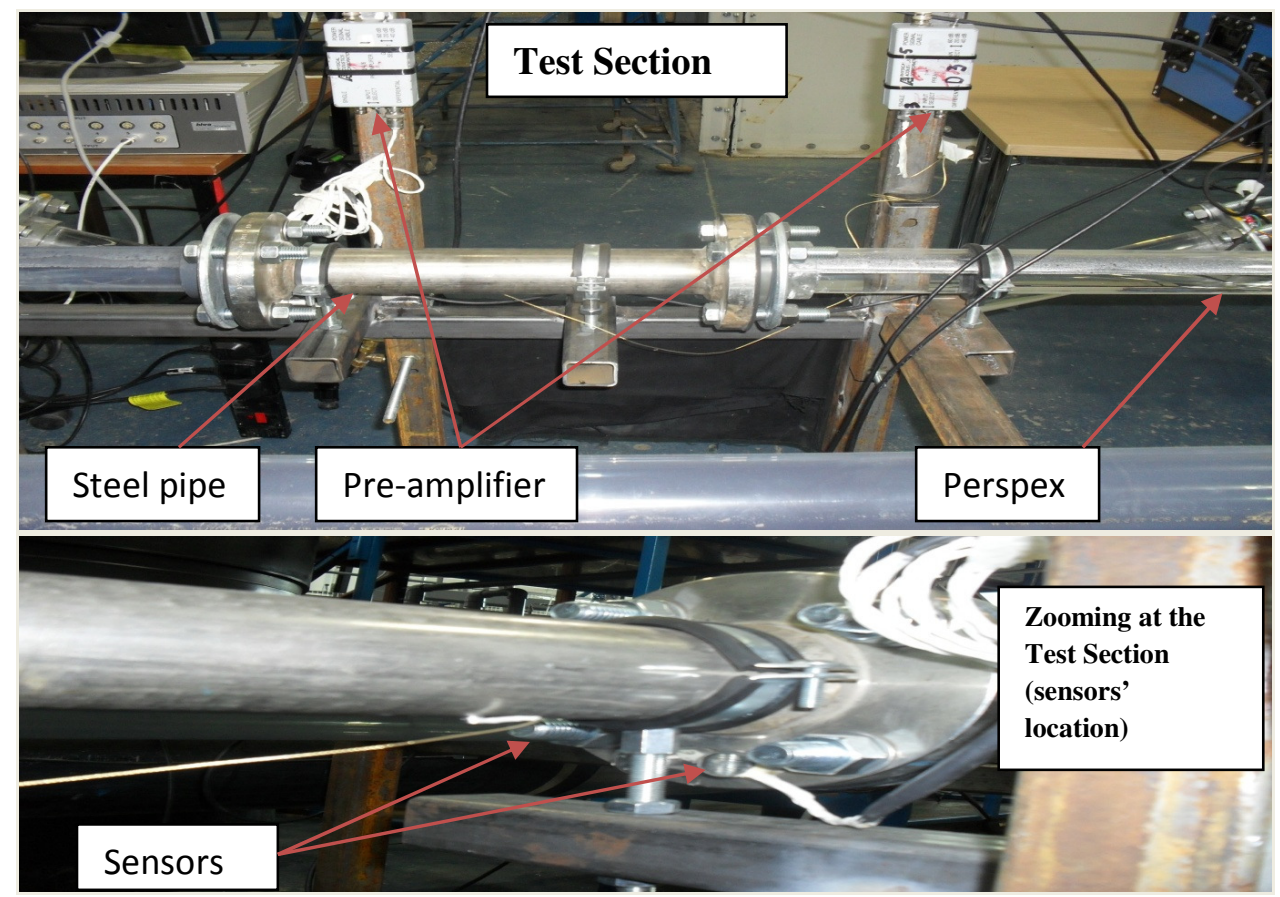

Fig.3. Test section of two-phase flow facility.

\section{EXPERIMENTAL RESULTS AND DISCUSSION}

\section{Preliminary experiment-fall impact test}

The waveforms obtained due to the impact of $500 \mu \mathrm{m}$ diameter sand particles dropped from a height of $20 \mathrm{~cm}$ onto a $1.5 \mathrm{~mm}$ thick steel plate were recorded, and a typical AE time domain waveform is shown in Fig. 4 (top). A corresponding Gabor 
wavelet was generated, and can be seen in Fig.4 (bottom). The wavelet shows the intensity of the $A E$ waveform at each frequency over the duration of the signal.

Observations of the $\mathrm{AE}$ waveforms in Figs. 4 and 5 show the first $50 \mu \mathrm{s}$ to be associated with the initial impact of the sand particle on the steel plate. Thereafter, the sensor picks up the AE reflections from the edges of the plate and the secondary impact of the sand on the plate.

The corresponding time-frequency (wavelet) plot obtained from AE waveform data, as shown at the bottom of Figs. 4 and 5, shows high frequency content at various time locations. The waveforms show distinctive results for each different height test performed, where the maximum amplitude of the waveform for drop height of $60 \mathrm{~cm}$ was greater than the maximum amplitude of the waveform for drop-height $20 \mathrm{~cm}$. Similar results were obtained for the aluminium plate. For all test conditions, the greatest $A E$ energy levels were obtained using steel plate.

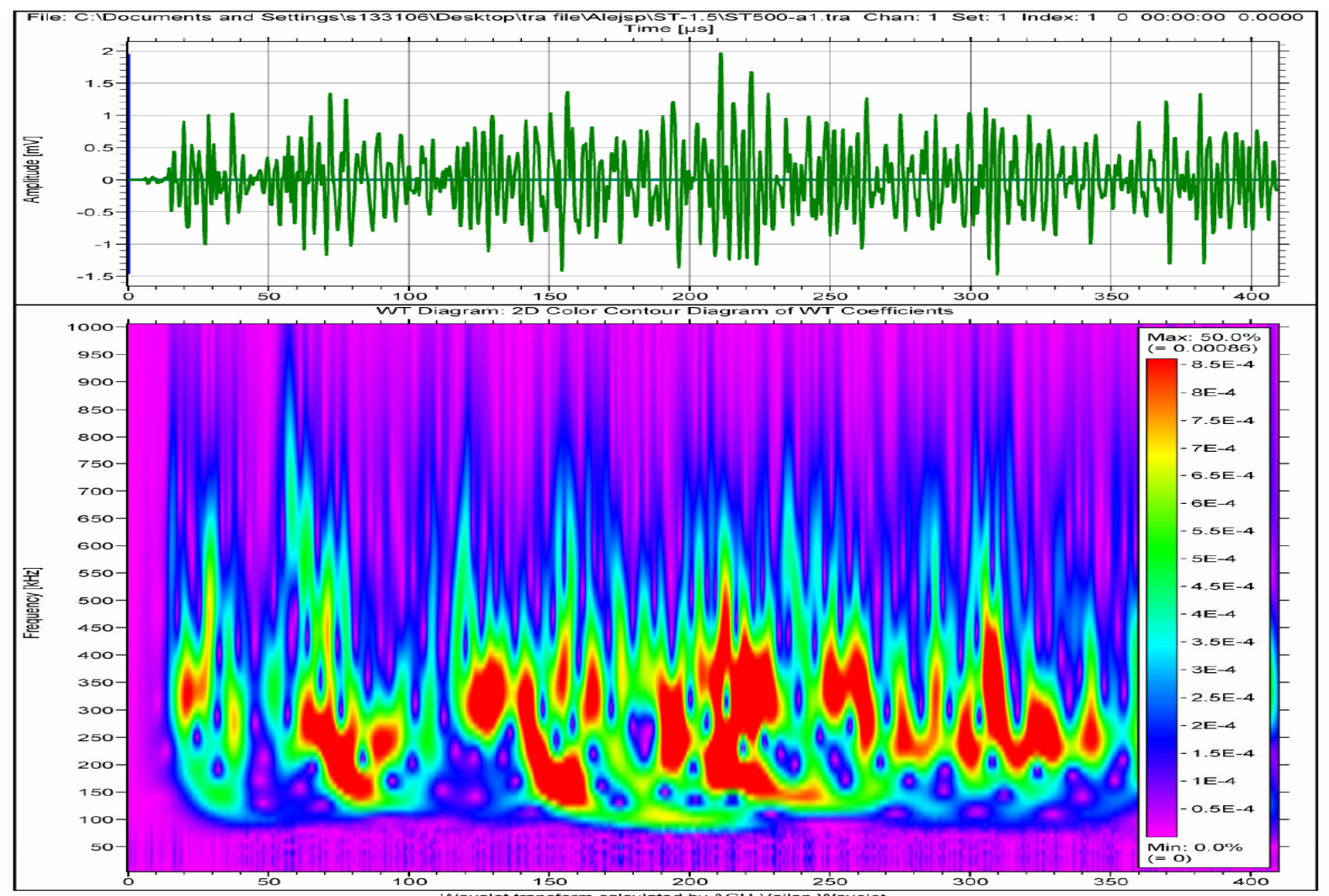

Fig.4. Time domain (top) and time frequency (bottom) plots for single sand particle of 500 $\mu \mathrm{m}$ diameter dropped onto a $1.5 \mathrm{~mm}$ thickness steel plate from a height of $20 \mathrm{~cm}$.

Observation of Figs. 4 and 5, reveals that the impact excited a broad frequency range covering $100 \mathrm{kHz}$ to $700 \mathrm{kHz}$, with the highest intensity between $100 \mathrm{kHz}$ to $400 \mathrm{kHz}$. Also interestingly the time-frequency map associate with the initial impact $(<50 \mu \mathrm{s})$ shows remarkable similarity in the distribution of frequency intensity irrespective of drop height, see Figs. 4 and 5 . Such repeatability was encouraging for analysis of the multiphase test condition. Fig.6 shows that the AE absolute energy was proportional to the size of particle and drop height, with steel demonstrating more AE energy for each impact. 


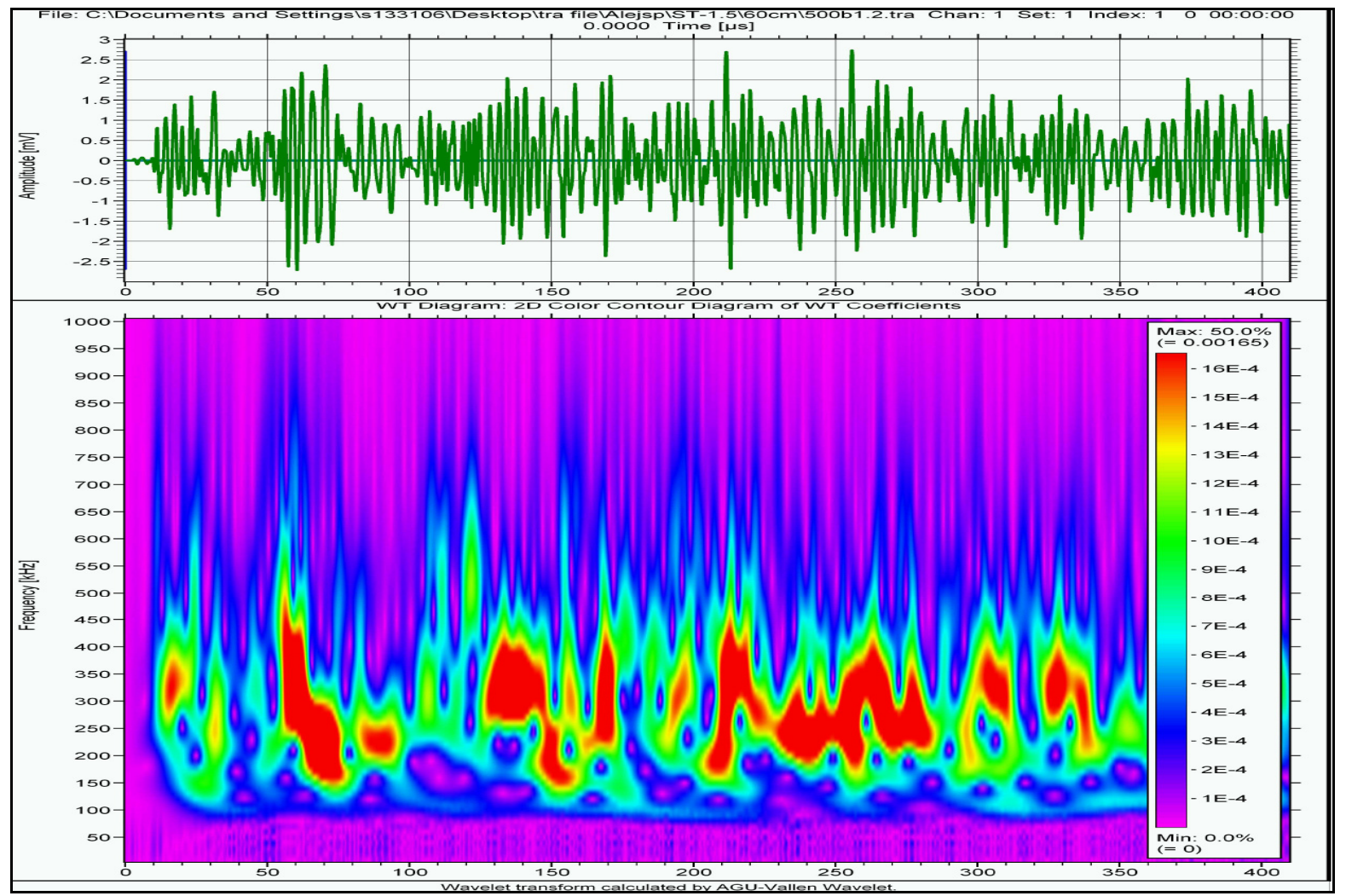

Fig.5. Time domain (top) and time frequency (bottom) plots for single sand particle of 500 $\mu \mathrm{m}$ diameter dropped onto a $1.5 \mathrm{~mm}$ thickness steel plate from a height of $60 \mathrm{~cm}$.

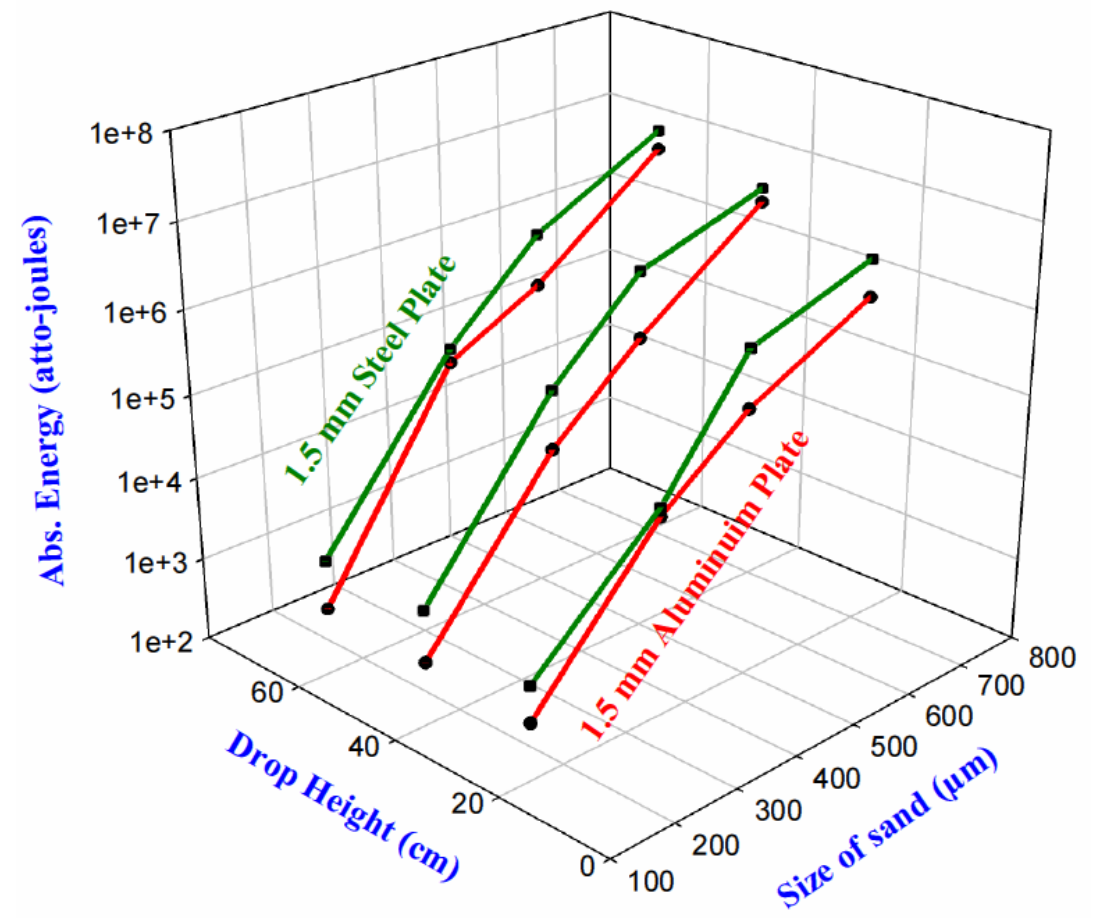

Fig.6. AE Absolute Energy for sand particle of diameter $500 \mu \mathrm{m}$ impacting on metal plates of thickness of $1.5 \mathrm{~mm}$, for drop heights of $20 \mathrm{~cm}, 40 \mathrm{~cm}$, and $60 \mathrm{~cm}$. 
The measured energy (signal energy) in an AE signal is calculated as

$$
\text { Signal Energy }(\mathrm{SE})=1 / \mathrm{R} \int_{0}^{T} v^{2}(t) d t
$$

Where $v(t)$ is the time dependent voltage from the AE sensor, and $T$ the duration of the entire event over which the integration is performed. This energy is directly proportional to the electrical energy of the AE signal in the measured bandwidth by a constant of system electric impedance [9], which in this instance was $10 \mathrm{k} \Omega$.

Observation of Fig.7 shows that when a sand particle was dropped onto $1.5 \mathrm{~mm}$ thick aluminium plate there was an average increase of $60 \%$ in signal energy when the drop height was increased from $20 \mathrm{~cm}$ to $60 \mathrm{~cm}$. The corresponding increase for steel plate of $1.5 \mathrm{~mm}$ thickness was about $65 \%$. In addition it can also be observed that the signal energy associated with the steel plate was on average about $50 \%$ higher than aluminium for drop heights of $20 \mathrm{~cm}$ and $65 \%$ higher for drop heights of $60 \mathrm{~cm}$. Fig.7, shows the signal energy for a single sand particle of $500 \mu \mathrm{m}$ diameter dropped onto $1.5 \mathrm{~mm}$ thick aluminium and steel plates for drop heights of $20 \mathrm{~cm}$ and $60 \mathrm{~cm}$.

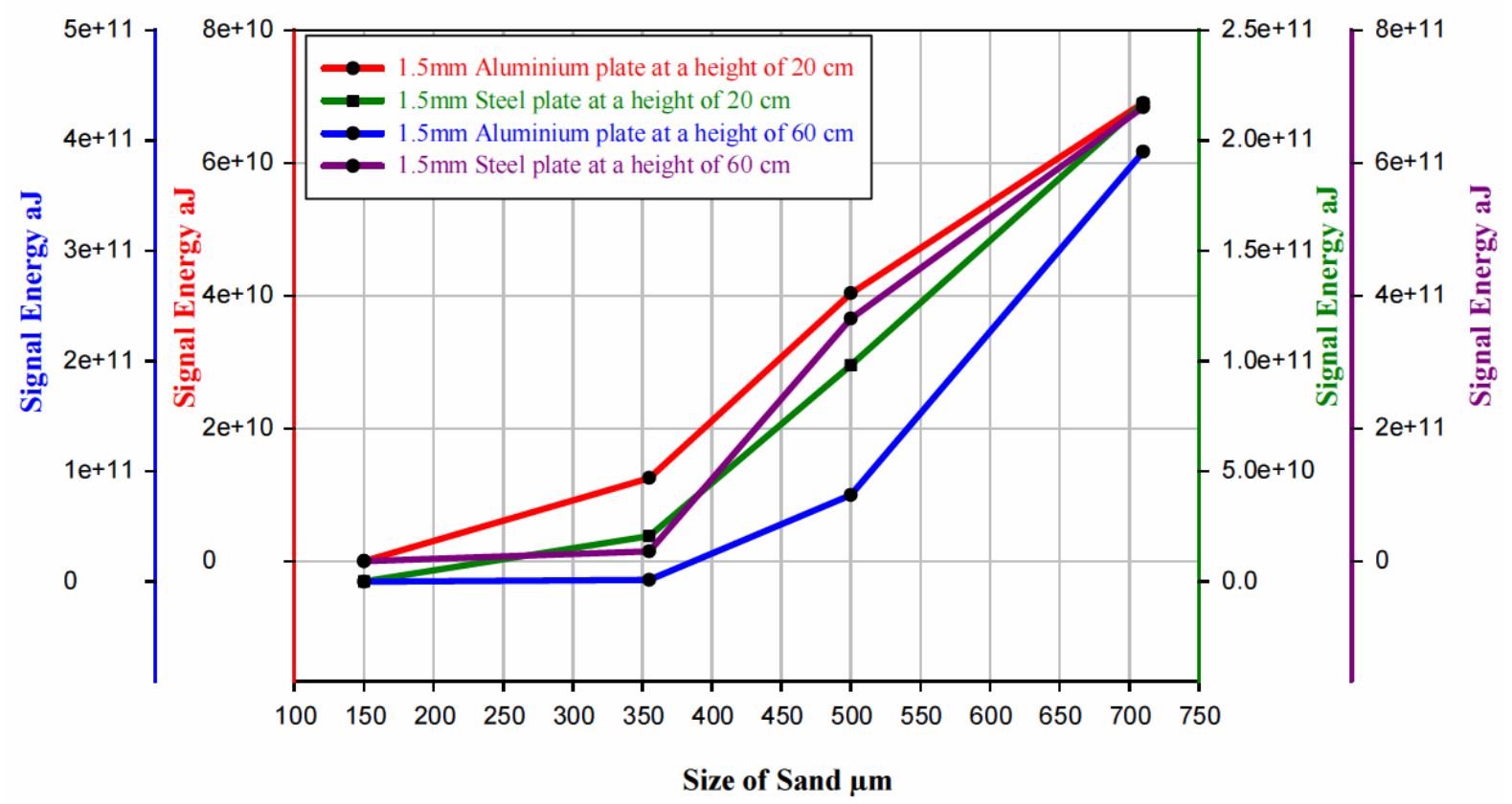

Fig.7. AE signal energy for sand particle of diameter $500 \mu \mathrm{m}$ at dropped from heights of $20 \mathrm{~cm}$ and $60 \mathrm{~cm}$ impacting on metal plates of thickness $1.5 \mathrm{~mm}$.

Figure 8 compares the potential energy and the signal energy at drop heights of $20 \mathrm{~cm}$ and $60 \mathrm{~cm}$ for steel plates. The potential energy was generally implicitly assumed in the energy considerations of $A E$ [10]. The mechanical potential energy is calculated as:

Potential Energy $=\mathrm{m} \mathrm{g} \mathrm{h}$ (Joule) 
where $g$ is the gravity acceleration constant $\left(9.81 \mathrm{~m} / \mathrm{s}^{2}\right), \mathrm{h}$ is the drop height and $\mathrm{m}$ is the mass of the sand particle in $\mathrm{kg}$.

It is a well known that, when a sand particle impacts onto a metal plate, it produces an elastic waves that propagates in all directions, and can be detected by an appropriate sensor. These waves contain frequencies that range from just over $0 \mathrm{~Hz}$ to several $\mathrm{MHz}$. However, here the measurements of $\mathrm{AE}$ are restricted to between $100 \mathrm{kHz}-1 \mathrm{MHz}$. Furthermore, some energy is dissipated as heat. Therefore, the measured $A E$ absolute energy obtained from measurement with the $A E$ sensor will always be significantly less than the theoretical estimate of potential energy obtained from the impact of sand particle on the plate.

It can be seen from Fig. 8 that the AE signal energy represents about $4 \%$ of the magnitude value of the potential energy when the drop height was $20 \mathrm{~cm}$, and almost $6 \%$ when the drop height was $60 \mathrm{~cm}$. Increasing the drop height from $20 \mathrm{~cm}$ to $60 \mathrm{~cm}$ theoretically increases the potential energy by $70 \%$ and the measured signal energy by almost $75 \%$.

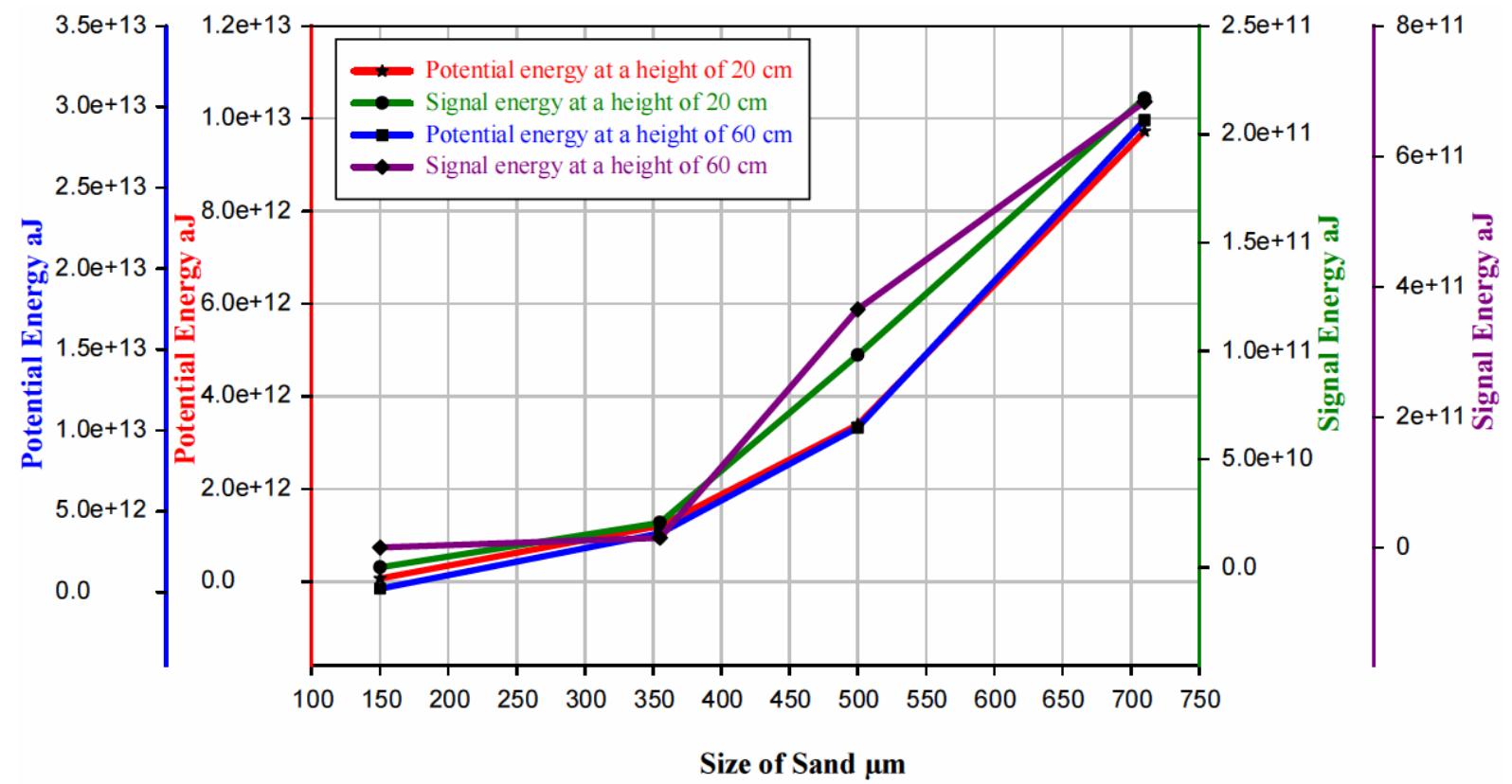

Fig.8. Comparison between potential \& signal energy of sand particle up on impact on steel plate at drop heights of $20 \mathrm{~cm}$ and $60 \mathrm{~cm}$.

\section{Two-phase flow test using $50 \mathrm{~mm}$ (2 inch) pipe}

The experiment was conducted using a single sand particle and one hundred sand particles of diameters $355 \mu \mathrm{m}, 425 \mu \mathrm{m}, 500 \mu \mathrm{m}, 600 \mu \mathrm{m}, 710 \mu \mathrm{m}, 800 \mu \mathrm{m}$. The sand particles were fed/injected into the pipe at selected VSG values: $5.8 \mathrm{~ms}^{-1}, 6.9 \mathrm{~ms}^{-1}$, $8.2 \mathrm{~ms}^{-1}, 9.3 \mathrm{~ms}^{-1}$ and $10.5 \mathrm{~ms}^{-1}$.

In gas-solid flows, flow regimes of both phases depend not only on the initial conditions and physical boundaries of the system but also on the mechanisms of 
momentum transfer or the interacting forces between the phases. The forces controlling the motions of particles may be classified into three groups: (1) forces through the interface between the fluid and particles; (2) forces due to the interactions between particles; and (3) forces imposed by external fields [11]. The flow regimes of gas-solid usually observed in horizontal pipes are; Homogeneous Flow, Dune Flow, Slug Flow, and Packed Bed. In this experiment the flow regime is a homogeneous flow.

The AE waveforms obtained for all of tests were recorded, and typical $A E$ waveforms for a single sand particle and one hundred sand particles of $425 \mu \mathrm{m}$ diameter at VSG of $9.3 \mathrm{~ms}-1$ are shown in of Figs.9 and 10.

The time domain waveform results presented in Fig.9, show several transient $A E$ bursts which imply repeating impingement/impact on the steel pipe's wall from a single sand particle injected into the air flow stream. These transient bursts are visibly separated from each other by duration in excess of $30 \mu \mathrm{s}$. In comparison, $\mathrm{AE}$ transient events observed for one-hundred particles, see Fig.10 were so closely coupled as to be of a continuous nature. The time-frequency plot for the first sand impacts on the pipe $(<25 \mu \mathrm{s})$, was different for the two cases both in terms of intensity and frequency range. The single particle impact shows a peak frequency at $20 \mu \mathrm{s}$ of $200 \mathrm{kHz}$ whilst the 'one hundred' particles showed a peak frequency range at $20 \mu \mathrm{s}$ of $200 \mathrm{kHz}$ to $550 \mathrm{kHz}$. The authors attribute this to multiple impacts resulting in significantly more $\mathrm{AE}$ energy. Moreover it was observed that peak frequency changes as the number, size of particles and air velocity changes.

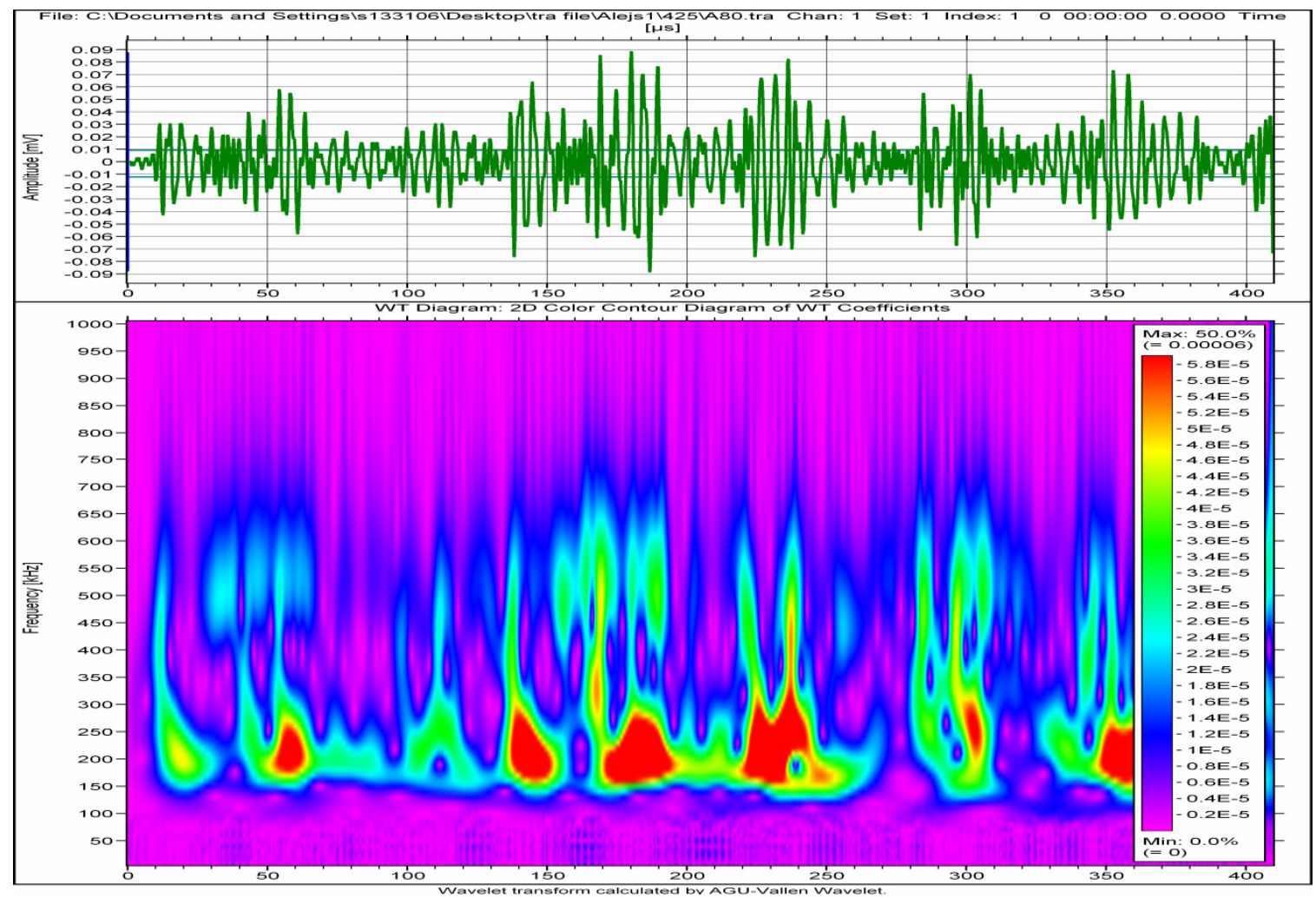

Fig.9. Time domain (top) and time frequency (bottom) plots for single sand particle of 425 $\mu \mathrm{m}$ diameter impacting on a steel pipe with VSG of $9.3 \mathrm{~m} / \mathrm{s}$. 
Figure 10 shows the maximum intensity of the $A E$ energy for one-hundred sand particles to be up to $650 \mathrm{kHz}$, whereas the maximum frequency of the most intense AE energy for one sand particle was $300 \mathrm{kHz}$, as shown in Fig. 9.

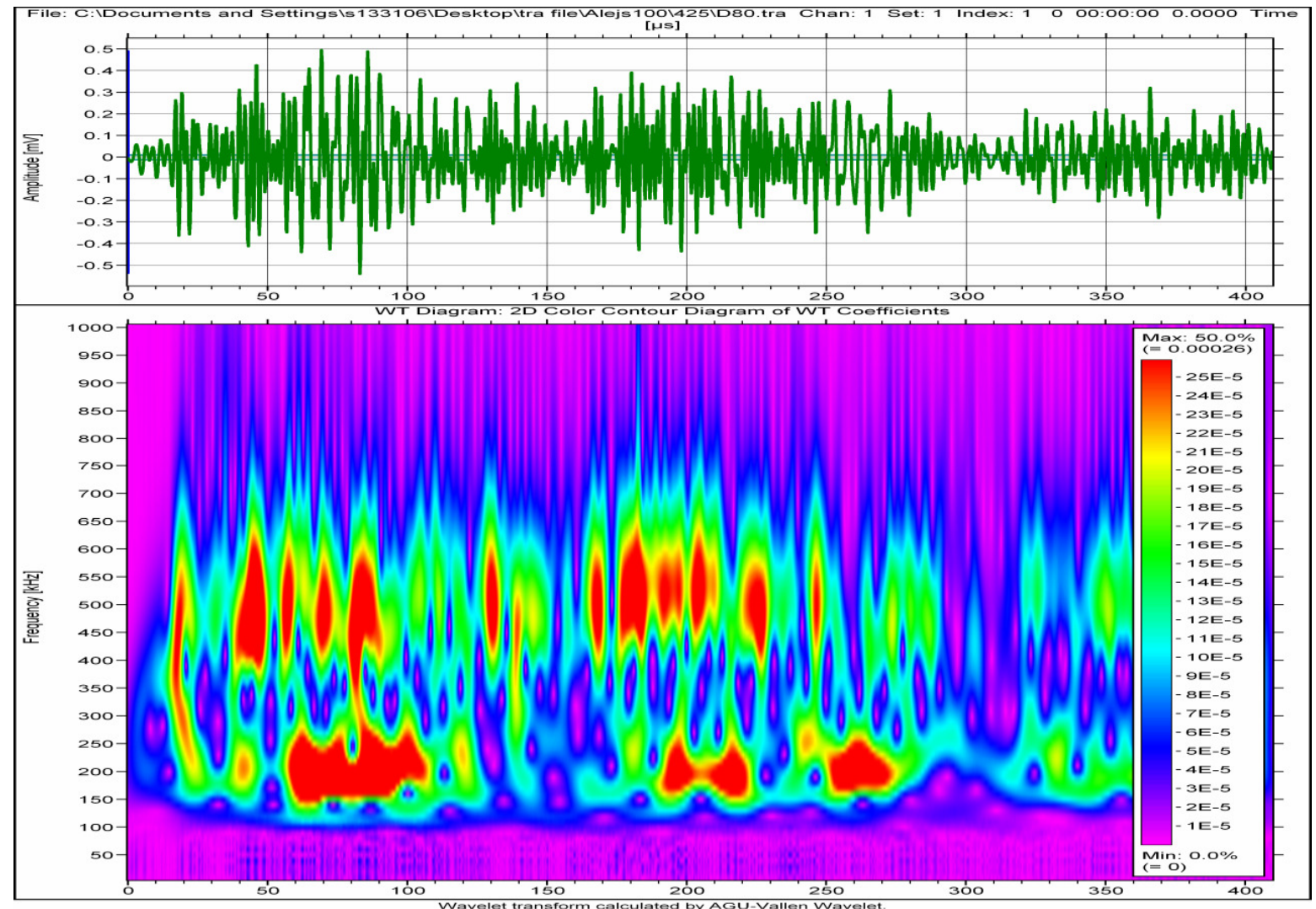

Fig.10. Time domain (top) and time frequency (bottom) plots for 100 sand particles of $425 \mu \mathrm{m}$ diameter impacting on a steel pipe with VSG of $9.3 \mathrm{~m} / \mathrm{s}$.

Figures 11 and 12 show waterfall results for the AE absolute energy obtained for a range of the two-phase flows of air-sand. Fig. 11 clearly shows a correlation between AE absolute energy for a single sand particle and both sand particle size and air velocity (VSG).

Air velocity or VSG is significantly influence on AE energy levels as shown in Fig. 11. The observations showed a general increase in the AE energy levels detected by the $A E$ sensors as the air velocity gradually increased from $5.8 \mathrm{~ms}^{-1}$ to $10.5 \mathrm{~ms}^{-1}$ for sand particles of sizes $355 \mu \mathrm{m}, 425 \mu \mathrm{m}, 500 \mu \mathrm{m}$ and $600 \mu \mathrm{m}$. Also, AE energy levels increased with size of sand particle. Typically, the shorter the distance of the $A E$ sensor from the impact point of the sand particle, the larger the magnitude of the $A E$ absolute energy. In some cases such as for sand particles of sizes $710 \mu \mathrm{m}$ and 800 $\mu \mathrm{m}, \mathrm{AE}$ energy levels acquired were randomly, these were expected as the distance from the source (sand particles) to the AE sensor was changeable. The influence of impact angle and the attenuation in the material forming the wall of the pipe have yet to be accounted for. 


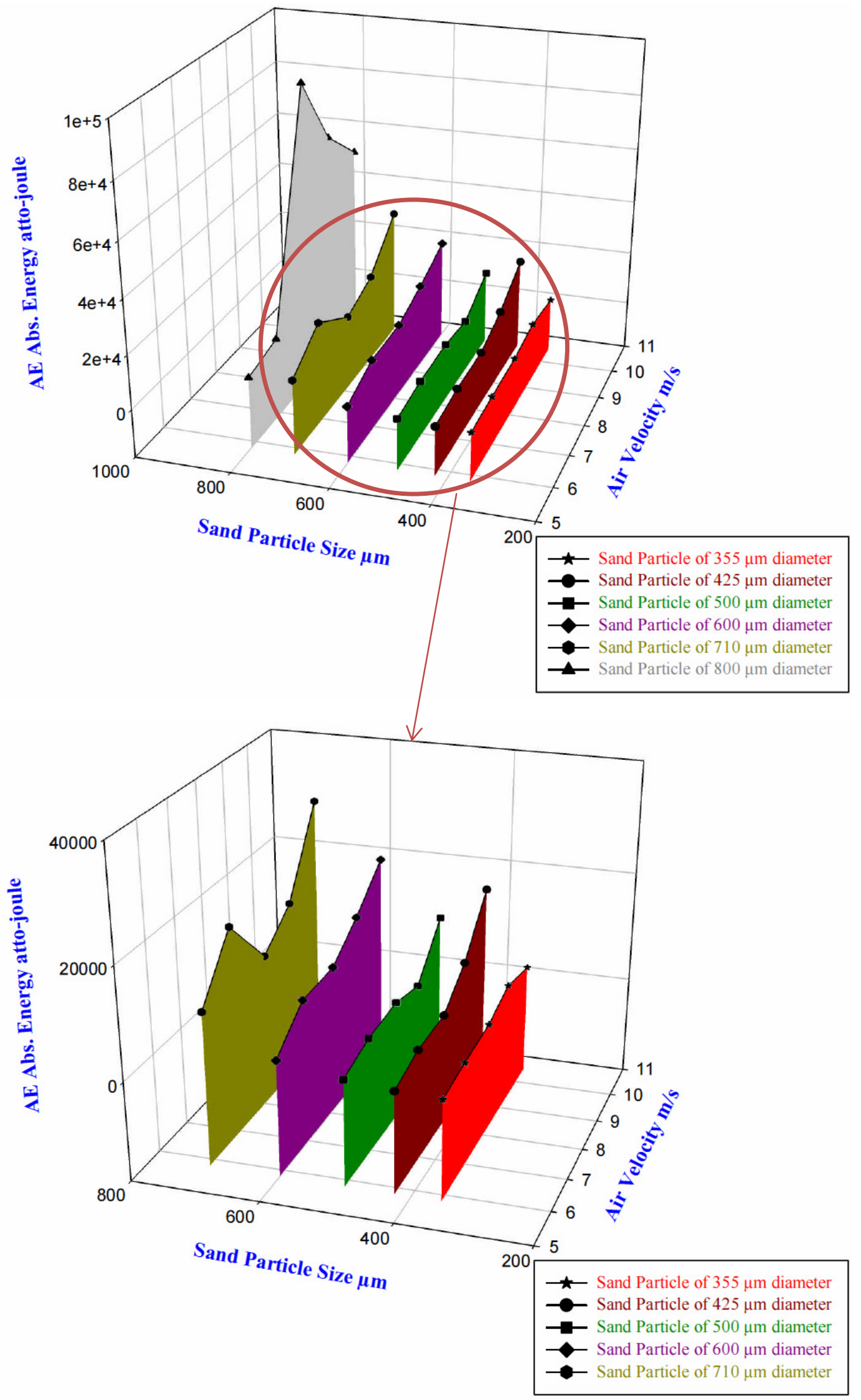

Fig.11. AE Absolute Energy for one particle of sand of diameter between $355 \mu \mathrm{m}$ and $800 \mu \mathrm{m}$, at selected air velocities between $5.8 \mathrm{~ms}^{-1}$ and $10.5 \mathrm{~ms}^{-1}$. 
Figure 12 also shows a correlation between $\mathrm{AE}$ absolute energy and the three parameters tested; sand particle size, VSG and number of sand particles. AE energy levels increase with increase in VSG for the same size of sand particles, and with increase in size of sand particle for the same VSG. Also, greater AE energy levels were observed when the number of sand particles was increased from one to hundred, see Figs. 11 and 12.

In two cases, less AE energy levels were noted when VSG is $9.3 \mathrm{~ms}^{-1}$ for sand particles size of $425 \mu \mathrm{m}$, and VSG is $10.5 \mathrm{~ms}^{-1}$ for sand particles of size $800 \mu \mathrm{m}$. These were expected due to the effect of some parameters such as; the lift force due to the shear flow, particle interactions, particle wall collisions, and pipe roughness and gravitational settling on AE energy levels.

\section{CONCLUSIONS}

The results obtained from the initial investigation have shown correlations between AE energy levels, sand particle size and the drop height of the particle. The larger the mass and the greater the drop height the greater is the force of impact and thus the greater the resulting AE energy. This simple result provides a fundamental result in the study of erosion phenomena.

The results obtained from the two-phase air-sand flow investigation clearly show correlation between AE energy levels, sand particle size, air velocity (VSG) and number of particles. AE energy levels increase with the strength of the impact, e.g. with increasing number of sand particles, size of sand particles and VSG.

This is the first reported attempt at monitoring AE energy associated with sand particle movement in a horizontal pipe. The successful detection of a single sand particle impacting on both a metal plate and metal pipe provides a basis for the application of $A E$ technology in monitoring three-phase gas-water-sand flows in pipeline transportation particularly in the oil and gas industry. 


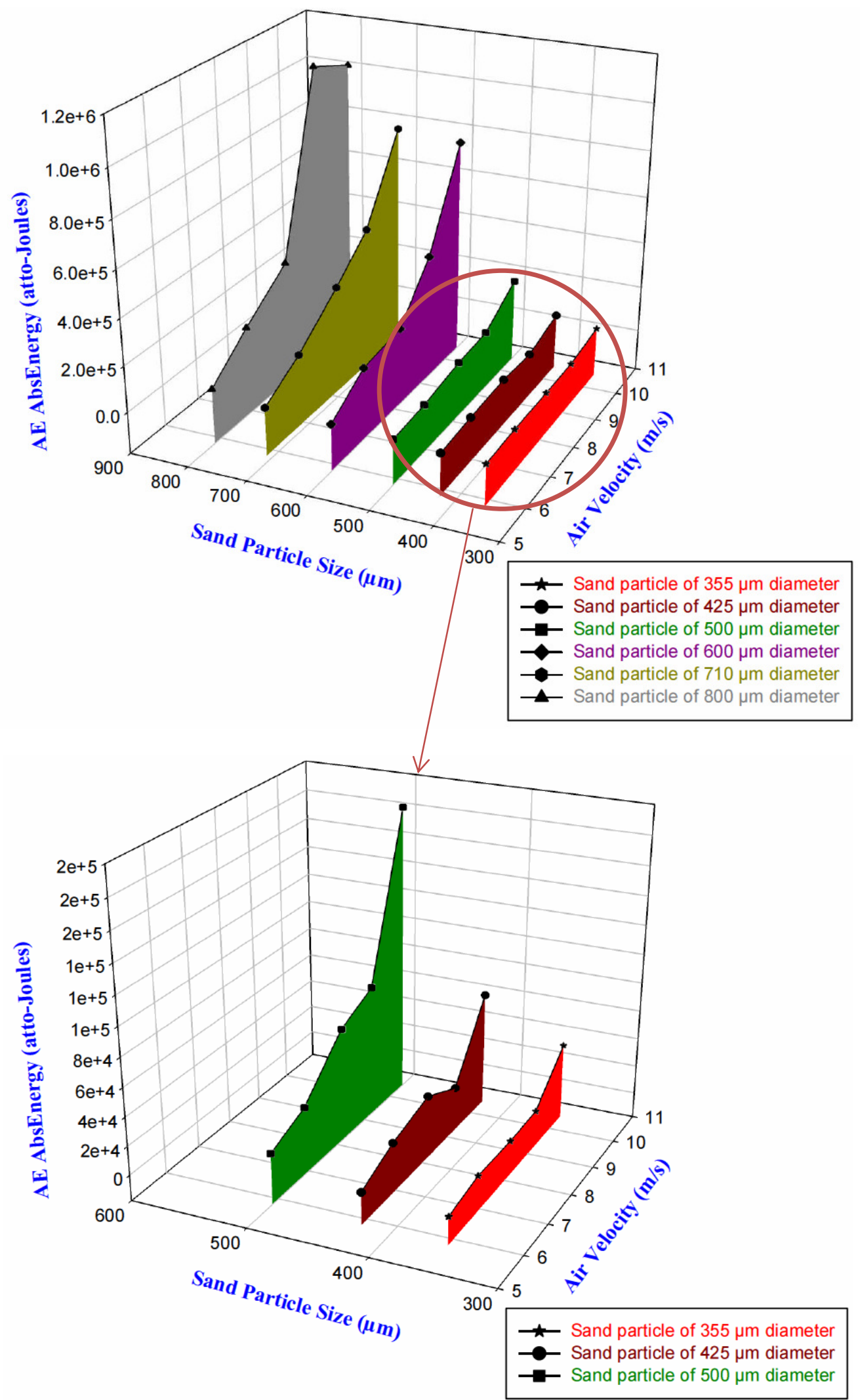

Fig.12. AE Absolute Energy for 100 particles of sand of diameter between $355 \mu \mathrm{m}$ and $800 \mu \mathrm{m}$, at selected air velocities between $5.8 \mathrm{~ms}-1$ and $10.5 \mathrm{~ms}-1$. 


\section{REFERENCES}

[1] S.A. Shirazi, B.S. McLaury, and M.M. Ali. (2000) The Erosion/Corrosion Research Centre, Department of Mechanical Engineering, The University of Tulsa, Tulsa, OK, 2000, Corrosion 2000, paper No. 00084.

[2] S. Al-lababidi, A. Addali, H. Yeung, D. Mba and F. Khan, (2010) Acoustic Emission and gas phase measurements in two-phase flow, Proc. IMechE Part E-Journal of Process Mechanical Engineering Volume: 224 Issue: E4 Pages: 281-290 Published: 2010.

[3] Husin, S. and Mba, D. (2010). Acoustic Emission of Single Bubble Activities. International Multi-Conference of Engineers and Computer Scientists 2010, London, $30^{\text {th }}$ Jun-2 ${ }^{\text {nd }}$ July, International Association of Engineers, ISBN: 978988-18210-7-2, ISSN: 2078-0958, PP. 1466-471.

[4] Husin, S., Folashade, A., Addali, A., and Mba, D. (2011) Observation of slug flow using acoustic emission. $24^{\text {th }}$ International Congress on Condition Monitoring and Diagnostics Engineering Management (COMADEM 2011), Stavanger, Norway, 30 ${ }^{\text {th }}$ May- $1^{\text {st }}$ June 2011.

[5] Al-Lababidi, S., Addali, A., Yeung, H., Mba, D. And Khan, K. (2009). Gas Void Fraction Measurement in Two-Phase Gas/Liquid Slug Flow Using Acoustic Emission Technology, Journal of Vibration and Acoustics, ASME, 131(6), 064501, PP. 693-702.

[6] FDIS ISO (International Standards Organization Documents) 22096. Condition monitoring and diagnosis of machines - Acoustic Emission. [22096]. 2007. International Standards Organization Documents.

[7] T. Holroyd. Acoustic emission \& ultrasonic, Series editor; Trevor M. Hunt, Coxmoor publishing company.

[8] J.Z. Sikorska and D. Mba, (2008) Truth, Lies, acoustic emission and process machines, Journal of Mechanical Process Engineering, Part E, IMechE, Volume 222, Number 1, 1-19.

[9] T. Yan and B. E. Jones (2000) Traceability of AE measurements using energy calibration methods, Measurement Science Technology, vol.11, L9L12.

[10] D.J. Buttle and C.B. Scruby, (1989) Characterization of particle impact by quantitative acoustic emission, Material physics and metallurgy division, Harwell Laboratory, Didcot, Oxfordshire (UK).

[11] R. W. Johnson (2000) Analyze Hazards, Not Just Risks, Chemical Engineering Progress.

[12] S. Al-Lababidi, W. Yan, and H. Yeung (2007). Sold Transport and Deposition Characteristics in Multiphase flow in pipelines, Dep. Of offshore, Process and Energy Eng. School of Eng. Cranfield University, UK. 